\title{
Do Shared Interests Affect the Accuracy of Budgets?*
}

\author{
Ilse Maria Beuren \\ Ph.D Professor, Department of Accounting Sciences, Federal University of Paraná \\ E-mail: illse.beuren@gmail.com
}

\section{Franciele Beck}

Ph.D Student, Department of Accounting and Actuarial Science, University of São Paulo

E-mail: beck.franciele@gmail.com

Fabiane Popik

Master, Department of Accounting, Barriga Verde University Center

E-mail: fabi_popik@yahoo.com.br

Received on 11.10.2013 - Desk acceptance on 11.22.2013 - $3^{\text {rd }}$ version accépted on 12.12.2014

\begin{abstract}
The creation of budgetary slack is a phenomenon associated with various behavioral aspects. This study focuses on accuracy in budgeting when the benefit of the slack is shared between the unit manager and his/her assistant. In this study, accuracy is measured by the level of slack in the budget, and the benefit of slack represents a financial consideration for the manager and the assistant. The study aims to test how shared interests in budgetary slack affect the accuracy of budget reports in an organization. To this end, an experimental study was conducted with a sample of 90 employees in management and other leadership positions at a cooperative that has a variable compensation plan based on the achievement of organizational goals. The experiment conducted in this study is consubstantiated by the study of Church, Hannan and Kuang (2012), which was conducted with a sample of undergraduate students in the United States and used a quantitative approach to analyze the results. In the first part of the experiment, the results show that when budgetary slack is not shared, managers tend to create greater slack when the assistant is not aware of the creation of slack; these managers thus generate a lower accuracy index than managers whose assistants are aware of the creation of slack. When budgetary slack is shared, there is higher average slack when the assistant is aware of the creation of slack. In the second part of the experiment, the accuracy index is higher for managers who prepare the budget with the knowledge that their assistants prefer larger slack values. However, the accuracy level differs between managers who know that their assistants prefer maximizing slack values and managers who do not know their assistants' preference regarding slack. These results contribute to the literature by presenting evidence of managers' behavior in the creation of budgetary slack in scenarios in which they share the benefits of slack with their assistants.
\end{abstract}

Keywords: shared interests, budgetary slack, benefit of slack, budget accuracy. 


\section{INTRODUCTION}

The budget is an integral part of the governance structure and may be the management tool used most often by organizations (Davila \& Wouters, 2005). The budget provides direction over a specific time period and is an important basis for evaluating the performance of the organization and its managers (Davila \& Wouters, 2005; Frezatti, Nascimento, Junqueira, \& Relvas, 2011). The latter purpose can lead managers to promote budgetary slack to facilitate the achievement of goals that are established and quantified in the budget (Yuen, 2004).

Budgetary slack is described as the attempt to facilitate achievement of budgetary goals by underestimating revenues, overestimating costs and/or exercising bias in setting goals. In this sense, slack represents the difference between budgeted resources and the resources actually needed to achieve the budgeted activities (Merchant, 1985; Moene, 1986; Lukka, 1988; Dunk \& Nouri, 1998; Nouri \& Parker, 1998; Kilfoyle \& Richardson, 2011).

In the study by Church, Hannan and Kuang (2012), which is utilized as the basis for this study, laboratory experiments were conducted to evaluate the creation of budgetary slack by managers. The authors defined slack as the difference between estimated cost and actual cost, which is consistent with the understanding of slack as the overestimation of costs in the budget.

The positivist perspective, which is the predominant view in the literature on budgetary slack, maintains that to the extent that "slack results in unnecessary expropriation of resources by the [sub] unit manager, it is not in the best interests of the overall organization" (Church, Hannan, \& Kuang, 2012, p. 1). Thus, based on the concepts of organizational efficiency and effectiveness, budgetary slack reflects an imbalance in the organization's goals and should be inhibited, which requires knowledge of slack's characteristics, motivations and effects.

Kilfoyle and Richardson (2011) note that the subject of the budget and its specific features, including budgetary slack, have been discussed in the literature under very diverse theoretical approaches, including agency theory, institutional theory and contingency theory. These authors suggest that the subject of "how agents' exposure to multiple institutional logics affects their experience of values conflict within budget processes" represents a fertile field of research concerning budgetary processes.

The development of this subject has increasingly incorporated elements of other theoretical approaches (Covaleski, Evans III, Luft \& Shields, 2003). Research on budgetary slack from the behavioral perspective, which is based on attitudes, motivations, behaviors, perceptions and other factors, has been guided by psychological theories such as moral disengagement (Bandura, 1990) and elasticity (Hsee, 1995), which enables the analysis of managers' inclination to create slack given different configurations of organizational control systems.

The operationalization of the budgetary slack phenomenon from the behavioral perspective has been the subject of studies that aim to test the reporting behavior of unit managers when they provide information to corporate headquarters (Evans III, Hannan, Krishnan, \& Moser, 2001). The benefit of slack translates into greater ease in achieving organizational goals; thus, if compensation is tied to organizational goals, slack may result in higher variable compensation for the manager and his/ her subordinates. In this context, the accuracy of budgetary reports, which is represented by the level of budgetary slack, assumes that the higher the slack value, the less accurate the budget.

Because the perceived benefit of slack is analyzed from the perspective of the individual managers and subordinates, Church et al. (2012) conducted a laboratory experiment to assess the accuracy of budget reports in various circumstances. In this experiment, college students were exposed to scenarios that differed based on (i) whether the benefit of slack was shared between the manager (who was responsible for preparing the budget) and the assistant (who was not involved in budget preparation); (ii) whether the manager had knowledge of the assistant's preference regarding the inclusion of slack in the budget; and (iii) whether the assistant had knowledge of the budgeted and actual costs.

Earlier studies addressed the impact of control system configurations on the creation of budgetary slack. For example, Chow, Cooper and Waller (1988) observed that the budgetary process has lower levels of slack under a truth-inducing configuration than it does under traditional configurations. Evans III, Hannan, Krishnan and Moser (2001) found that the level of slack in the budget, which is associated with the honesty of the budget report, may depend on how the budgetary surplus is divided between the manager and the company. Their study revealed that the configuration of employment contracts can influence managerial behavior. Rankin, Schwartz and Young (2005) investigated whether the need to obtain budget approval from a superior affected managers' creation of budgetary slack. The results indicated that slack is smaller when the manager has final authority over the budget than when a superior's approval is required.

The results of these studies show the impact of control system configurations on individuals' behavior. In addition, there is evidence in the literature that certain conditions (e.g., whether budgetary slack is shared between the manager and subordinates and whether subordinates have knowledge of the manager's creation of budgetary slack) can influence the levels of budgetary slack (Bandura, 1990; Hsee, 1995). Based on the above discussion, there is the potential to develop additional research on the subject, particularly regarding the ontological approach, theoretical and methodological perspectives, level of analysis, organizational type and other apparent research gaps.

Based on the theoretical and empirical findings discussed above, the following research question was elaborated: 
How does the presence of shared interests in budgetary slack affect the accuracy of budget reports in an organization? Thus, this study aims to test how shared interests in budgetary slack affect the accuracy of budgets in an organization. Accuracy is measured in this study based on (i) budgetary slack, which is defined as the intentional overestimation in the budget of the costs and resources required to perform specific tasks (Nouri \& Parker, 1998; Church et al., 2012), and (ii) the degree of honesty in the budget (the closer the index is to 1, the greater the accuracy of the budget) (Evans III et al. 2001; Rankin, Schwartz, \& Young, 2008). The relevance of the present study is that it seeks to understand budgetary slack, a phenomenon that is intrinsically linked to the behavior of the individuals involved in the budgetary process within an organization.

This study contributes to the consolidation of the theoretical principles underlying this research by developing empirical evidence of managerial behavior in the creation of budgetary slack. This research includes scenarios that differ based on whether the benefits of slack are shared with subordinates, whether the subordinates have knowledge of the managers' creation of slack, and whether the managers have knowledge of their subordinates' preferences regarding budgetary slack. This study yields inferences about the effects of control system configurations on the manager's propensity to create budgetary slack based on the self-justification of slack (Bandura, 1990) and about whether the elasticity of slack is affected by the manager's perception of whether slack is accepted by his/her group (Hsee, 1995).

This study also has intrinsic methodological appeal because it includes an experiment based on the design adopted in Church et al. (2012). This technique is not yet widely used in Brazilian behavioral research on phenomena in the managerial accounting area. Also noteworthy is the contribution of the experimental design, which is based on a hypothetical situation (Gall, Gall, \& Borg, 2007; Smith, 2011) that simplifies the budgeting process in an organization under certain moderating conditions and uses a sample of professionals who are accustomed to or at least knowledgeable about the application of budgeting processes in organizational practice.

Rankin, Schwartz and Young (2008) note that studies regarding the creation of budgetary slack indicate that corporate culture can have a profound effect on this behavior. Therefore, the use of professionals from a single institution in the experiment, albeit under a laboratory setting, generates important evidence because cultural elements will be maintained to a certain extent. Thus, performing the experiment with a sample consisting of managers and other leaders of a cooperative, who are accustomed to a reward system based on goals and to the daily life of an organization, contributes to the discovery of evidence about this phenomenon in organizational practice and in the specific group studied.

\section{BUDGETARY SLACK AND RELATED VARIABLES}

According to Bruns and Waterhouse (1975), budgets are financial plans that provide a basis to guide and evaluate the performance of individuals, work teams, company divisions and the organization as a whole. In addition, Bruns and Waterhouse (1975) assert that these plans, along with firm leadership and organizational structure, have the potential to influence organizational behavior. Yuen (2004, p. 517) warns that "the manner in which operational budgets are prepared and executed can have a significant impact on the attitudes, behavior, and performance of those involved".

Managerial behavior can be directed towards the propensity to create budgetary slack (Yuen, 2004). According to Dunk and Perera (1997), budgetary slack is the intentional underestimation of income/productive capabilities and the overestimation of costs/required resources to ensure easier compliance with the budget. In addition, under the positivist perspective, budgetary slack is viewed as a dysfunctional aspect of the organization; that is, it reflects a lack of control and/or distortions in the information used for decision making.

Although several variables related to budgetary slack are found in the literature, the predominance of the analysis focuses on variables from the economic paradigm and relies on agency theory assumptions (Covaleski et al., 2003).
Economic variables considered in the literature include the emphasis placed by the organization on the budget (Stede, 2000; Yuen, 2004), budgetary participation and information asymmetry (Merchant, 1985; Moene, 1986; Chow, Cooper, \& Waller, 1988; Lukka, 1988; Waller, 1988; Dunk, 1993; Lal, Dunk, \& Smith, 1996; Nouri \& Parker, 1998). These three variables have intertwined relationships with each other that are manifest in other variables, such as the informational level, information technology, performance-based compensation and other aspects.

However, this study views the creation of budgetary slack through the theoretical lens of psychology and thus focuses on the behavior and judgment of the individuals involved in the budget process, considering factors such as ethics, honesty, the inducement of truth through budgetary participation and incentive plans, and the perception of what is acceptable or not by peers involved in the budget process (Chow et al., 1988; Evans III et al., 2001; Rankin, Schwartz, \& Young, 2005; Maiga \& Jacobs, 2008; Hartmann \& Maas, 2010; Church et al., 2012).

Chow et al. (1988) studied the impact of reward schemes configurations (incentives) and information asymmetries on the creation of budgetary slack. These authors analyzed the preparation of participative budgets under a 
truth-inducing compensation system that incentivized managers to set budgets equal to their expected performance. The experiment revealed that budgets prepared under this truth-inducing compensation scheme had lower levels of slack than budgets prepared under traditional pay schemes.

Evans III et al. (2001) analyzed honesty in an environment where the managers of business units possessed superior information that headquarters needed to make efficient operating decisions; one manner in which this information was transmitted from managers to headquarters was through budget reports. Their experiments revealed that the honesty of managers played an important role in the preparation of budget reports. The results suggest that managerial reports are influenced by relative preferences for honesty and wealth and that the degree of managerial honesty may depend on how the total budgetary surplus is divided between the manager and the company. That study addresses budgetary slack from the perspective of agency theory and illustrates that the configuration of contracts can affect managerial behavior.

Following Evans III et al. (2001), Rankin et al. (2005) studied the creation of budgetary slack in situations that differed based on whether the subordinate or a superior had the final authority to approve the budget. They observed that the slack is significantly smaller when the subordinate has final authority over the budget than when the superior's approval is required. This result demonstrates that the configuration of control systems can affect individuals' behavior.

This field of research is expanding to "gain a better understanding of how agents' exposure to multiple institutional logics affects their experience of values conflict within budget processes and how this affects the institutional logics that are embedded within budgets" (Kilfoyle \& Richardson, 2011 , p. 195). This topic raises the issues of organizational control system design and the perceptions and interactions of the individuals involved in the budgeting process.

According to Simons (1995), the managerial control system comprises four levers that together facilitate the achievement of organizational goals. The first lever comprises belief systems, which communicate the core values of the company and include the company's mission and vision statements. Belief systems guide employees' behavior by establishing organizational expectations. The second lever refers to boundary systems, which are the organizational codes and procedures that employees must follow. The third lever consists of diagnostic control systems, which are embodied in various mechanisms used by the company to establish and monitor the achievement of organizational objectives. Diagnostic control systems include the organization's budget and incentive system. The fourth lever refers to interactive control systems, the purpose of which is to promote the identification of opportunities and the development of emergent strategies.

In the managerial control model proposed by Simons (1995), the organization seeks to align its goals with the means to achieve those goals. For example, incentive compensation policies are an important factor to be considered in the budget process because these policies influence the extent to which the benefit of slack is shared between managers and employees (Church et al., 2012). The authors also indicate that organizations are increasingly implementing group-based incentive plans.

A group-based incentive compensation scheme is characterized by the fact "that compensation varies as a function of performance achieved by a group of employees" (Hollensbe \& Guthrie, 2000, p. 864). Accordingly, Church et al. (2012) conclude that the creation of budgetary slack through the underestimation of group targets would yield shared benefits for the manager and employees of the affected unit. Thus, the configuration of the managerial control system and its specifications can influence the behavior of individuals in an organization.

According to Bandura (2002), individuals in their daily actions adopt standards of right and wrong that serve as guides and that are developed as a type of morality itself. Individuals monitor their conduct taking into account the conditions under which it occurs and judge that conduct based on their moral standards. The concept of moral agency (Bandura, 2002) is embedded in a broader socio-cognitive theory that encompasses self-regulatory mechanisms that are based on personal standards and linked to self-sanctions.

Osofsky, Bandura and Zimbardo (2005, p. 371) explain that "in the exercise of moral agency, people refrain from behaving in ways that violate their moral standards because such conduct will bring self-condemnation." In contrast, Moore (2008, p. iii) highlights Bandura's (1990, 1999, 2002) moral disengagement theory, which describes a contrary mechanism developed by individuals, namely, "the generalized tendency to evoke cognitions which suspend the self-regulatory processes that typically direct our moral behavior."

According to Church et al. (2012), moral disengagement occurs when a manager associates the inclusion of slack in the budget with a benefit that is shared with others (employees). Put differently, because the creation of slack does not benefit the manager alone but rather serves a common interest, the manager creates a self-justification for his/her conduct. This common interest leads to less accurate reports that are characterized by higher rates of slack.

The process of moral disengagement by the individual takes into account the organization's social context. Abul-Ezz and Dickhaut (1993, p. 17) explain that social norms can influence a group's performance and can even prescribe "how a group member should perform in a given situation." These authors analyze the budget process and performance expectations when the budgetary results are shared by a group.

The intensity of individuals' moral disengagement may be associated with elastic justification, which is based on the theory of elasticity (Hsee, 1995, 1996). This theory addresses how a manager's budgetary decisions are influenced by various justifiable and unjustifiable factors. Unjustifiable factors refer to factors that the manager would like to take into consideration but knows that he/she should not.

In this study, the theory of elasticity is applied to managers' decisions regarding whether to include slack in the budget and (if the decision is made to include slack) whether to include the maximum possible amount of slack or 
a smaller amount that the manager perceives as justifiable (Church et al., 2012). These decisions involve the manager's perception of whether this behavior is approved by his/her subordinates. Thus, managers' self-justification in preparing the budget involves the selection of the best possible alternative.

Studies on budgetary slack are found in Brazilian journals, but these studies reveal the recent emergence of this subject in the national context. Specifically, the Brazilian studies focus on mapping the key topics in the budgetary slack literature (Junqueira, Oyadomari, \& Moraes, 2010; Pereira, Bruni, Lamb \& Son, 2012) and identifying, from an interpretative perspective, the issues related to the creation of budgetary slack in a company (Frezatti, Beck, \& Silva, 2013).

Among the Brazilian studies that analyze factors associated with the creation of budgetary slack, as this study does, the following studies are highlighted: Aguiar and Souza (2010); Beuren and Paton (2013); Buzzi, Santos, Beuren and Faveri (2014); and Lavarda and Fank (2014). Aguiar and Souza (2010) conducted a study in a hospital and found that managers were inclined to create slack in the budget as a means of establishing easily achievable goals. The managers were also influenced by their understanding of the dissociation between budgetary goals and cost control.

Beuren and Paton (2013) examined the determinants of organizational slack from the perspective of business unit (BU) controllers at a company with a decentralized structure. The results indicated that the degree of orga- nizational slack differed according to (i) the emphasis on reaching budget targets; (ii) the extent of information asymmetry between the general manager of the BU and the corporate controller; (iii) whether the controller of the $\mathrm{BU}$ had the authority to make decisions regarding employee management and to make changes in technical and accounting procedures; and (iv) the autonomy of the BU.

Buzzi et al. (2014) observed the relationship between budgetary slack, managerial participation in the budget and organizational emphasis on the budget and found evidence that managers tend to create greater budgetary slack when there is significant emphasis on the budget and information asymmetry exists. The study by Lavarda and Fank (2014) indicated that there is no relationship between the creation of budgetary slack and participation, information asymmetry or risk. Thus, the results of Brazilian research on this subject are inconclusive, as previously noted by Junqueira, Oyadomari and Moraes (2010), which confirms the potential for the development of research on this topic in the Brazilian context.

The studies discussed in this theoretical framework facilitate an understanding of the current status of budgetary slack research in the managerial accounting literature, in both international and Brazilian contexts. Moreover, these studies provide elements that promote an understanding of managerial behavior during the budget process and, in particular, how this behavior is influenced by whether subordinates are aware of the manager's budgeting behavior.

\section{DESCRIPTION OF THE STUDY BY CHURCH, HANNAN AND KUANG (2012)}

The experiment conducted by Church et al. (2012) with U.S. undergraduate students is discussed in detail below because that study substantiates the present study. Church et al. (2012) studied (i) the accuracy of budget reports when budgetary slack creates a benefit and (ii) the extent to which budgetary accuracy depends on whether the benefit is shared between the manager (who is responsible for drafting the budget report) and the assistant (who is not involved in the preparation of the budget report).

The study of Church et al. (2012) had two objectives. The first was to investigate how shared interests affected the accuracy of budget reports or, more specifically, how sharing the benefits of budgetary slack between the unit manager, who prepares the budget report, and the assistant, who is not involved in its preparation, affected the accuracy of budget reports. The second objective was to investigate whether the manager's behavior was affected by the manager's knowledge of the assistant's preference regarding the inclusion of budgetary slack. The authors conducted two behavioral experiments in laboratory settings to achieve these research objectives.
3.1 Experiment 1 - Sharing or not sharing the benefit of budgetary slack/the assistant has knowledge or does not have knowledge of the manager's creation of slack

In Experiment 1, Church et al. (2012) studied how shared interests between the manager and assistant affected the accuracy of budget reports.

Based on the moral disengagement theory of Bandura (1990, 1999, 2002), the authors noted that misreporting by the manager to create budgetary slack is considered morally unjustifiable and negative when it only benefits the manager. However, if the benefits of budgetary slack are shared between the manager and assistant, misreporting to create budgetary slack tends to be viewed positively because it serves a common interest, which justifies the misreporting and makes it morally permissible. Based on this understanding, the authors developed the first hypothesis regarding shared interest:

$\mathrm{H}_{1}$ - Managers create less accurate budget reports when the benefit of the slack is shared with the assistants than when the benefit of slack is not shared. 
The managers' concern about their assistants' perceptions regarding the preparation of inaccurate budgets was also studied. Arguably, when the benefit of slack is not shared, the manager worries about whether the assistant perceives him/her as opportunistic and selfish. Thus, when the benefit of slack is not shared, the manager would tend to report with greater accuracy when the assistant is aware of the manager's choices. However, when the benefit of slack is shared with the assistant, the accuracy of the budget reports will likely be affected by the assistant's knowledge of the manager's choices. Thus, the authors formulated two hypotheses relating to the assistants' knowledge of managers' inaccurate statements in budget reports:

$\mathrm{H}_{2 \mathrm{a}}$ - If the benefit of the budgetary slack is not shared, managers report with greater accuracy when the assistants are aware of the manager's reporting behavior than when the assistants are not aware of the manager's reporting behavior.

$\mathrm{H}_{2 \mathrm{~b}}$ - If the benefit of the budgetary slack is shared, the accuracy of the budget reports prepared by managers is not affected by the assistants' knowledge of the manager's reporting behavior.

To test these hypotheses, the experiment was conducted in a behavioral research laboratory. A report configuration similar to a "trust contract" (Evans III et al., 2001) was used in the first experiment because this type of contract allows researchers to investigate the effect of behavioral factors when participants have significant economic incentives to act opportunistically.

A total of 174 undergraduate students who were enrolled in various majors at the Georgia Institute of Technology in the United States participated in the experiment. The participants were located in the same room but interacted anonymously with each other. For the experiment, half of the individuals in the sample were assigned the role of unit manager and the other half were assigned the assistant role. Each unit manager presented a budget report to a hypothetical headquarters in which he/she requested funds to finance the unit's production costs. The manager knew the exact cost of production before submitting the budget report, and headquarters provided funds equal to the budgeted amount as long as the amount was viable. The authors opted not to have any participants take on the role of headquarters.

Two factors were manipulated in the experiment. The first factor related to whether the benefit of budgetary slack was shared between the manager and the assistant. When slack was shared, the value of the difference between the estimated and actual costs (the slack) was split between the manager and assistant. When slack was not shared, the manager received the full value of the slack. The second manipulated factor was whether the actual and budgeted costs were known by the assistant. Knowledgeable assistants were informed of both the actual cost and the amount budgeted by the manager; unknowledgeable assistants were not informed of the actual cost or the budgeted amount. The manager was aware of the assistant's condition as knowledgeable or unknowledgeable.

The experiment consisted of six separate steps; that is, the actual costs and budget reports in one step had no consequence on any other step. For better comparisons between managers, the actual costs were determined randomly for the six steps, and all managers received the same actual cost at every step. At each stage of the experiment, the same basic procedures were performed. After the six steps of the experiment were completed, the participants playing the role of managers completed a post-experiment questionnaire.

Two measures were calculated to assess the accuracy of the managers' budget reports. The first, called "slack", was computed as the difference between the budgeted cost and the actual cost. The second, called "accuracy", was adapted from Evans III et al. (2001) and calculated with the following formula: 1 - [(budgeted cost - actual cost $) /(6,000$ - actual cost $)]$. This formula resulted in a value of zero to one. If a manager behaved honestly, reporting the actual cost, the value was one; on the contrary, if the manager maximized self-interest by reporting the maximum possible amount (6,000 Liras, a fictitious currency used in the experiment), the value was zero.

To test the first hypothesis, the authors conducted analysis of variance (ANOVA) to compare the means of the two groups. The dependent variables were each manager-participant's slack and accuracy in each of the six stages of the experiment. The results indicated that managers presented less accurate budget reports when the benefit of slack was shared with assistants than when the benefit was not shared; thus, $\mathrm{H}_{1}$ was confirmed.

In the post-experiment questionnaire, managers were asked whether they thought their assistants preferred a budget that included slack, preferred a budget in which the budgeted cost equaled the actual cost or were indifferent to the inclusion of slack in the budget. In their responses, most managers indicated that when the benefit of slack was not shared, they perceived that the assistants either preferred a budgeted cost equal to the actual cost or were indifferent to slack. However, when the benefit of the slack was shared, nearly all managers indicated that they thought that the assistant preferred a budgeted cost greater than the actual cost. This result demonstrated managers' assumption that assistants prefer budgets with slack when the benefit of slack is shared.

With respect to the second set of hypotheses, $\mathrm{H}_{2 \mathrm{a}}$ (when the benefit of slack is not shared, assistants' knowledge of the managers' reporting behavior increases the accuracy of budget reports) was not confirmed. This indicates that managers have little concern about whether assistants perceive them as opportunistic and selfish. However, $\mathrm{H}_{2 \mathrm{~b}}$ (when the benefit of slack is shared, assistants' knowledge of the managers' reporting behavior does not affect the accuracy of budget reports) was confirmed.

The post-experiment questionnaire asked managers to indicate how concerned they were about the impressions they made on assistants. The responses indicated 
that managers were not very concerned about assistants' impressions of them. However, the results of the experiment suggest otherwise; specifically, the assistant's knowledge of the creation of slack by the manager had no effect on the manager's behavior only when the slack also benefitted the assistant.

\subsection{Experiment 2 - The manager has knowledge or does not have knowledge of the assistant's preference regarding the inclusion of slack in the budget \\ In Experiment 2, Church et al. (2012) investigated whe-} ther the manager's budget reporting behavior was influenced by whether he/she had knowledge of the assistant's preference regarding the inclusion of slack in the budget. The authors based this experiment on Hsee's $(1995,1996)$ theory of elasticity, which states that the degree to which an individual engages in opportunistic behavior depends on the elasticity to justify the opportunistic behavior. The evidence suggests that if managers know that assistants prefer more honest budget reports, the managers' elasticity is reduced. Thus, managers are less likely to manipulate costs in budget reports when their assistants prefer honest budgets than when their assistants' preference is unknown or when their assistants' prefer to inflate the budget. The authors formulated the following hypothesis:

$\mathrm{H}_{3}$ - Managers who know that their assistants prefer more honest budget reports demonstrate greater reporting accuracy than managers who are aware that their assistants prefer wealth maximization or managers who do not know their assistants' preference.

Church et al. (2012) also tested whether the behavior of managers who know that their assistants prefer to inflate the budget differs from the behavior of managers who do not know their assistant's preference. The assumption was that the manager's knowledge that the assistant preferred to inflate the budget would have a limited incremental effect on the manager's reporting behavior. However, because the authors did not have a basis on which to accurately predict the magnitude of this incremental effect, a fourth null hypothesis was proposed.

$\mathrm{H}_{4}$ - The level of reporting accuracy will not differ between managers who are aware that their assistants prefer wealth maximization and managers who do not know their assistants' preference.

The same configuration and conditions used in the first experiment were used in Experiment 2. A total of 90 undergraduate students enrolled in different majors at the University of Georgia in the United States participated in the experiment. The experimental design focused on three levels of assistant preference: honest, selfish or unknown. The three levels were obtained by measuring each assistant's preference using a questionnaire.

The experiment was conducted in two phases. The first consisted of only assistants, and the second consisted of only managers. In the first phase, participants were informed that they would be assistants and that after being paired with a manager in a later session, they would be paid based on the manager's decisions. Assistants were asked to indicate the extent to which they thought the budget should be inflated from the actual cost.

In the second phase, managers were told that they had been paired with an assistant and that the assistants would be paid based on the manager's decisions. Managers whose assistants preferred honest or selfish budgets were informed of that preference. Then, these managers received a cost report containing information about the actual cost (which was one of the costs used in Experiment 1) and decided the amount to budget. Finally, the managers completed a post-experiment questionnaire and were released.

ANOVA was used to test hypotheses $\mathrm{H}_{3}$ and $\mathrm{H}_{4}$ by comparing the means of the two groups. Budgetary slack and the honesty of budget reports were the dependent variables, and the assistants' preferences (honest, selfish or unknown) were the independent variables. The tests confirmed both $\mathrm{H}_{3}$ and $\mathrm{H}_{4}$, that is, if the assistant has a known preference for more honest budget reports, the manager's reporting decision will be inelastic because the common interest provides less justification for inflating the budget. Thus, the manager is less inclined to inflate the budget in this situation. However, if the assistant's preference is unknown or favors wealth maximization, the manager will be more inclined to inflate the budget.

The post-experiment questionnaire asked managers about the extent to which their assistants' preference influenced their reporting decisions. The responses indicated that the managers' decisions were independent of the assistants' preferences.

\section{METHODOLOGY}

To investigate how shared interests in budgetary slack affect the accuracy of an organization's budget reports, the experiments developed and applied by Church et al. (2012) were used as a baseline. The study presented here is characterized as an experimental study because it involves the simplification of a situation (budget preparation) and allows the identification of the cause and effect of the analyzed variables through observation in a controlled environment (Gall et al., 2007; Smith, 2011).

\subsection{Study Sample}

The sample for the experiment consisted of $90 \mathrm{ma}-$ nagers and other leaders of a production cooperative in the South of Brazil. The roles of managers and assistants 
were randomly assigned to the participants, which is recommended by the literature (Smith, 2011) and in line with the procedure used in the baseline study.

The selection of this sample was based on the cooperative leaders' accessibility and the managers' and leaders' availability to participate. In addition, cooperatives belong to a sector that remains relatively unexplored in academic research. Conducting the experiment using a hypothetical situation in an established organization is a contribution of this study, given that Smith (2011) notes the need for experiments conducted with experienced professionals in the field.

Note that the use of the same sample to conduct the two experiments in this study differs from the procedure adopted by Church et al. (2012). However, this difference does not affect the analysis because the hypotheses for each experiment in the baseline study implied continuity rather than an intention to compare the results of the two samples.

\subsection{Adjustments to the Experimental Design Used in the Baseline Study}

The data were collected through an experiment that was based on the designs of the two experiments in Church et al. (2012). To operationalize its application to a Brazilian organization, the study was translated into Portuguese and analyzed to establish the procedures necessary to obtain the data and to perform further analysis. An experimental route was thereby established.

Because certain aspects of the experiments conducted in the baseline study were only cursorily addressed by Church et al. (2012), it was necessary to draw certain inferences based on the limited descriptions of the procedures used. The experiment conducted in this study follows the within-subjects factorial design, in which study participants maintain their respective roles (manager or assistant) and perform the sequential steps established in the experiment (Smith, 2011). The experimental design is presented in Table 1.

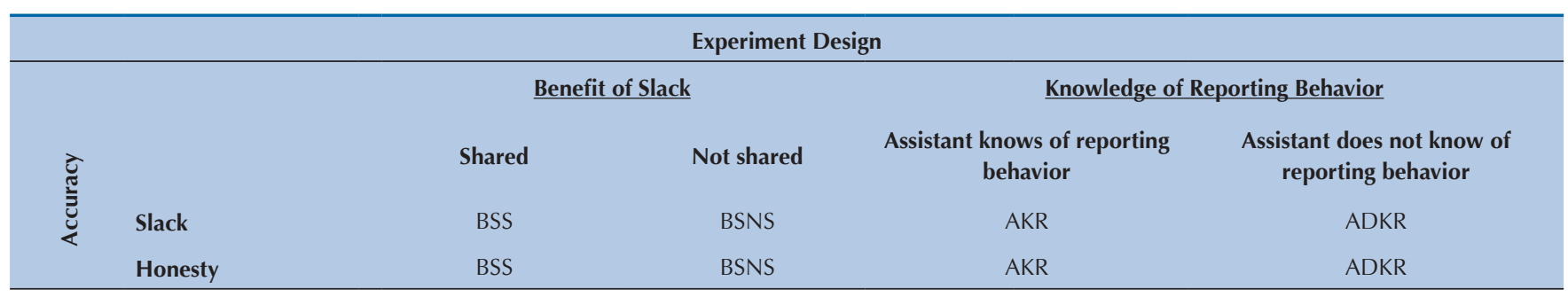

$\mathrm{H} 1$ - Managers present less accurate budget reports when the benefit of slack is shared with their assistants than when it is not shared.

$\mathrm{H} 1$ : Slack (BSS) > Slack (BSNS)

Honesty (BSS) < Honesty (BSNS)

$\mathrm{H} 2 \mathrm{a}$ - If the benefit of budgetary slack is not shared, managers present more accurate budget reports when the assistants are aware of managerial reporting behavior than when assistants are not aware of managerial reporting behavior.

H2a: Slack (BSNS, AKR) < Slack (BSNS, ADKR)

Honesty (BSNS, AKR) > Honesty (BSNS, ADKR)

$\mathrm{H} 2 \mathrm{~b}$ - If the benefit of budgetary slack is shared, the accuracy of managers' budget reports is not affected by assistants' awareness of managerial reporting behavior.

H2b: Slack and Honesty (BSS, AKR) = Slack and Honesty (BSS, ADR)

\begin{tabular}{clc}
\hline & & $\begin{array}{c}\text { Manager Knows the Assistant's Preference } \\
\text { (Honest/ Slack/ Indifferent) }\end{array}$ \\
Slack & KAP (KAP-H; KAP-S; KAP-I) \\
& Honesty & KAP (KAP-H; KAP-S; KAP-I) \\
\hline
\end{tabular}

$\mathrm{H} 3$ - Managers who know that their assistants prefer more honest budgets present more accurate budget reports than managers who know that their assistants prefer budgets with slack or managers who know that their assistants are indifferent to slack.

H3: Slack $($ KAP-H) < Slack (KAP - S / KAP-I)

Honesty $($ KAP-H) > Honesty $($ KAP - F / KAP-I)

$\mathrm{H} 4$ - The accuracy of budget reports does not differ between managers who know that their assistants prefer budgets with slack and managers who know that their assistants are indifferent to slack.

H4: Slack and Honesty (KAP-S) = Slack and Honesty (KAP-I)

Slack: Budgeted Cost - Actual Cost. The lower the value of the slack, the greater the accuracy of the budget.

Honesty: 1 - (Budgeted Cost - Actual Cost) / (6000 - Actual Cost). The closer the honesty index is to 1, the greater the accuracy of the budget. 
The conditions under which the experiment was conducted and the characteristics of sample participants necessitated adjustments to the experiment's design when it was conducted at the cooperative. For example, a symbolic compensation system was not used because the selected sample consisting of managers and other leaders of an organization that has an incentive plan based on meeting budgetary goals. Thus, symbolic economic incentives were not used in this experiment; rather, participants considered a realistic hypothetical situation of economic incentives.

Note that the literature on budgetary slack suggests that the creation of slack may be associated with the use of the budget as a basis for performance evaluation and compensation. Therefore, the decision of Church et al. (2012) to include participant compensation in their experimental design was not only a means to make the experiment more appealing to undergraduates but also a way to test the predictions presented in the literature on the subject. Removing this variable from the present experiment may affect the results and thus any comparison between the results of this study and the results of the baseline study must take this difference into account.

Another modification was the consolidation of the two experiments in Church et al. (2012) into a single experimental design due to the limited availability of the participants. It is also acknowledged that the implementation of the experiment as a hypothetical situation within an organization may affect participants' decisions due to the participants' accumulated knowledge based on organizational experiences. However, although participants' actions and the study results may be affected, this limitation is typical of experiments (Smith, 2011).

The literature regarding the application of this research method (Gall, Gall, \& Borg, 2007; Smith, 2011) notes that it is important to detect potential problems created by the experimental design. For example, participants may change their behavior based on what they think is expected of them. Participants may also make presumptions about expected behavior as they gradually learn the experimental design. Finally, fatigue can affect participants' behavior.

We tried to mitigate the effects of these limitations by adding to the dependent variables (sharing or not sharing the benefit of slack/knowledge or no knowledge of slack) in every step of the experiment. Thus, each budget report prepared by the managers and reviewed (or not reviewed) by the assistants contained a new element and thus differed from the budget report in the previous step. The addition of new elements to the budget reports was an attempt to observe participants' behavior regarding the creation of budgetary slack in these settings and to prevent the possible influence of the experimental design on participants' behavior.

The experiment was executed at the organization over approximately one hour. The researchers endeavored to conduct the experiment over a time period that was sufficient for data collection and without prejudice to data quality, which made it necessary to avoid causing fatigue in the participants. Thus, in addition to the active participation of the researchers, a support team of two people were responsible for the distribution, collection and organization of budget sheets during the experiment.
Based on the nature of the actions performed in the experiment, it is believed that the characteristics of the final data achieved the study's objective and that internal validity was maintained in the experimental design. However, a comparison of the results of this study and the results of Church et al. (2012) requires caution in light of the differences between them.

\subsection{Experimentation Guide Based on Church, Hannan and Kuang (2012)}

The experiment was conducted in the cooperative's facilities, which enabled the participation of its managers and leaders and respected each individual's willingness to participate. Among the individuals present when the experiment was conducted, three decided not to participate. Additionally, although participants were permitted to withdraw at any time during the experiment, in accordance with ethical research protocol, all 90 participants completed the experiment.

The assistance of a support team that was knowledgeable about the entire experimental design facilitated the performance of the experiment. The presentation of the study to the participants explained clearly that i) the objective of the experiment was to test how shared interests in budgetary slack affect the accuracy of budget reports; ii) budgetary slack referred to the difference between actual cost and budgeted cost, and the difference in value was considered a benefit to those involved in budget preparation; iii) in this experiment, it was assumed that the manager prepares the budget and that the manager always knows the exact cost of the products; iv) headquarters (the parent company) did not verify whether the budgeted amount was equal to the actual cost and would provide funds equal to the cost estimated by the manager as long as that cost was within a certain range (the value of the hypothetical product was between BRL 4,000.00 to BRL 6,000.00); and v) if the slack was shared, $50 \%$ of the slack value was allocated to the manager and $50 \%$ was allocated to the assistant.

Next, the sample was randomly divided into two subgroups. The participants were instructed that the individuals in one group would play the managers (responsible for budget preparation) and the individuals in the other group would play assistants (not responsible for budget preparation). Each participant randomly received an identification number that would be noted by the participant when requested, and this number was used for all steps of the experiment. It was emphasized that the identification number would be used solely for purposes of the experiment and that it would not have any relationship to the true identity of the participant. Cross-identification did not occur and in fact was not possible at any time during the experiment or data analysis.

Each group was directed to a different side of the room so that visual and auditory contact was precluded, except that all participants could see the researchers. The experiment then commenced.

\subsubsection{First part of the experiment}

$1^{\text {st }}$ stage: Manager does not share the slack and the assistant is not aware of the manager's reporting behavior 
The manager was given a cost sheet (with the actual cost already determined) and was asked to fill in the budgeted amount and his/her identification number. At this stage, the manager was asked to assume that he alone benefited from the slack and that the assistant did not know either the actual cost or the budgeted cost.

The information was filled in manager-participants over a short time period without any communication among them, after which the experiment team collected the cost sheets and proceeded to the second stage.

\section{$2^{\text {nd }}$ stage: Manager does not share the slack and the assis- tant is aware of the manager's reporting behavior}

Once again, the manager received a cost sheet (with the actual cost already determined) and was asked to fill in the budgeted amount and his/her identification number. In this step, the manager was asked to assume that only he/she benefited from the slack and that the assistant was aware of both the actual cost and the budgeted cost. After the information was filled in, the experiment team collected the cost sheets and proceeded to the third stage.

\section{$3^{\text {rd }}$ stage: Assistant reviews the budget proposed by the manager in the $2^{\text {nd }}$ stage}

The assistants randomly received the sheets that were completed by the managers in the second stage. The assistant was asked to review the information provided in the sheet and to note his/her identification number where indicated. The sheets were then collected, and the fourth stage began.

\section{$4^{\text {th }}$ stage: Manager shares the slack and the assistant is not aware of the manager's reporting behavior}

In this step, the manager was asked to assume that the benefit of slack was shared and that the assistant was not aware of either the actual cost or the budgeted cost. New cost sheets (with the actual cost already determined) were provided, and the manager was asked to fill in the budgeted amount and to provide his/her identification number. The cost sheets were then collected and the experiment proceeded to the fifth stage.

\section{$5^{\text {th }}$ stage: Manager shares the slack and the assistant is aware of the manager's reporting behavior}

The manager received a new cost sheet (with the actual cost already determined) and was asked to fill in the budgeted amount and to provide his/her identification number. The manager was asked to assume that the benefit of the slack was shared and that the assistant was aware of both the actual cost and the budgeted cost. The completed sheets were collected and the sixth stage commenced.

\section{$6^{\text {th }}$ stage: Assistant reviews the budget proposed by the manager in the $5^{\text {th }}$ stage}

The sheets completed by the managers in the fifth stage were randomly given to the assistants. The assistants were asked to review the information and to record their identification numbers where indicated. After the sheets were completed by the assistants, the managers were given a post-experiment questionnaire.

The post-experiment questionnaire contained two questions. The first question asked about the managers' perceptions regarding their assistants' preferences. Specifically, managers were asked to indicate whether they believed that i) the assistant preferred that the budgeted amount exceeded the actual cost; ii) the assistant preferred that the budgeted amount equaled the actual cost; or iii) the assistant did not care whether the budgeted amount was greater than or equal to the actual cost. The second question asked managers to indicate their degree of concern about their assistants' preferences regarding budget preparation on an 11-point scale, where 1 to $4=$ Little, 5 to $7=$ Indifferent and 8 to $11=$ Very Much.

For better comparability, the actual costs provided to the managers were randomly determined and all managers received the same actual cost at each stage. To evaluate the accuracy of the managers' budget reports, two measures (budgetary slack and honesty in budget reports) were calculated by replicating the formulas used in Church et al. (2012), which are described in section 3.1 of this study.

\subsubsection{Second part of the experiment}

The second part of the experiment began with the administration of a questionnaire to the assistants. The questionnaire asked the assistants to indicate the extent to which they agreed that the budget should be inflated in relation to actual cost on an 11-point scale, where 1 to $4=$ Should not be inflated, 5 to $7=$ Indifferent and 8 to $11=$ It should be inflated to the maximum extent. After the questionnaires were completed, the responses were tabulated and classified into one of three categories: Honest (Scale 1-4), Indifferent (Scale 5-7) and Slack (Scale 8-11).

A new experimental round was conducted in which the preferences indicated by each assistant in response to the questionnaire were recorded on individual cost sheets. The cost sheets were then randomly assigned to managers so that the managers could prepare the budget. Thus, the manager was aware of his/her assistant's preference when preparing the budget.

After the manager prepared the budget and noted his/ her identification number, the sheets were collected. Then, a post-experiment questionnaire was given to managers. The questionnaire asked managers to indicate the extent to which they cared about the assistant's preference regarding slack when determining the budget. An 11-point scale was used, where 1 to $4=$ Little, 5 to $7=$ Indifferent and 8 to $11=$ Very much. Once the post-experiment questionnaire was collected, all participants were thanked for their participation and the experiment concluded.

The data from the two parts of the experiment, which were collected in May 2012, were separated according to the different variables and situations analyzed and were then organized and tabulated according to the stage of the experiment. Descriptive statistics were used for mean slack and mean degree of accuracy. The parametric ANOVA test and the nonparametric Kruskal-Wallis test were applied to 
test the hypotheses that were established by Church et al. (2012) and replicated in this study, albeit with some adjust- ments to hypotheses $\mathrm{H} 3$ and $\mathrm{H} 4$, as previously described in the experimental design portion of this paper.

\section{DESCRIPTION AND ANALYSIS OF THE RESULTS}

\subsection{Results of the First Part of the Experiment}

The first part of the experiment aimed to test the hypotheses of this study by investigating how shared interests affected the accuracy of budget reports. Accuracy was measured in each of the six stages of the first part of the experiment, resulting in the means and standard deviations shown in Table 2.

Tabela 2 Descriptive analysis of the accuracy of budget reports - first part of the experiment

\begin{tabular}{|c|c|c|c|c|c|c|}
\hline \multirow[t]{2}{*}{ Interests } & \multirow[t]{2}{*}{ Accuracy } & \multicolumn{2}{|c|}{ Unknown (ADNR) } & \multicolumn{2}{|c|}{ Known (AKR) } & \multirow[t]{2}{*}{ Expected Relationship } \\
\hline & & Average & S.D. & Average & S.D. & \\
\hline \multirow{2}{*}{$\begin{array}{l}\text { Not shared } \\
\text { (BSNS) }\end{array}$} & Budgetary Slack & 770.56 & 613.83 & 370.22 & 374.06 & $(\mathrm{AKR})<(\mathrm{ADKR})$ \\
\hline & Honesty & 0.56 & 0.35 & 0.59 & 0.42 & \\
\hline \multirow{2}{*}{$\begin{array}{l}\text { Shared } \\
\text { (BSS) }\end{array}$} & Budgetary Slack & 255.33 & $255 / 27$ & 430.89 & 387.68 & $(A K R)=(A D K R)$ \\
\hline & Honesty & 0.64 & 0.36 & 0.61 & 0.35 & \\
\hline Expected Relationship & & \multicolumn{2}{|c|}{$(\mathrm{BSS})>(\mathrm{BSNS})$} & \multicolumn{2}{|c|}{$(\mathrm{BSS})>(\mathrm{BSNS})$} & \\
\hline
\end{tabular}

Source: Study data.

Table 2 shows significant variation in the means for each experimental condition. When the benefits of slack are not shared, managers tend to create greater budgetary slack when the assistant is unaware of the creation of slack (mean slack of 770.56 and mean honesty index of 0.56 ) than in the situation in which the assistant is aware of the creation of slack (mean slack of 370.22 and mean honesty index of 0.59).

Although the mean honesty indices in these experimental conditions were similar ( 0.56 and 0.59 ), the standard deviation shows that when the assistant is aware of the manager's reporting behavior, the honesty index is up to 0.42 away from the mean index, which indicates high variability between the budgeted amounts. That is, although 18 managers presented budget reports without slack, 9 managers presented reports that included the maximum allowable slack. When the assistant is unaware of the manager's reporting behavior, there is a standard deviation of 0.35 . In this situation, only 6 managers opted for a budget without slack; the remaining managers created slack in their reports at various levels within the permitted values.

When the manager shares the budgetary slack, the results show a higher mean slack when the assistant is aware of the manager's reporting behavior (430.89). In this situation, 23 managers have an honesty index higher than the mean index (0.61) and the other $22 \mathrm{ma}$ nagers exhibit lower indices, with a standard deviation of 0.35 relative to the mean honesty index. Under this experimental condition, managers showed greater accuracy when the assistant was not aware of the situation, with an honesty index of 0.64 . Despite the variability of the indices observed in the standard deviation (0.36), 29 managers chose to prepare their budgets without slack in this situation, and only 6 created the maximum permitted amount of slack.

The higher means observed in situations in which slack is not shared and the assistant is not aware of the manager's reporting shows that in the sample studied, the manager's personal interest and his/her concern about the impression made on the assistants prevailed. These results are inconsistent with the fundamentals of the moral disengagement theory (Bandura, 1990, 1999, 2002), which suggests that the practice of increasing budgetary slack is attributable to the common interest justification. This inconsistency requires a more in-depth analysis and discussion to determine whether that hypothesis is rejected or not.

To test hypothesis $\mathrm{H}_{1}$, a t-test to assess the homoscedasticity of the data was performed. The t-test showed significance at the $5 \%$ level for the slack variable. For the honesty variable, the t-test showed a high variability of variances between groups, without significance. Next, in line with Church et al. (2012), an ANOVA was conducted with slack and honesty as the dependent variables and sharing and not sharing as the independent variables.

The statistical results are described in Table 3 . Table 3 also presents the results of the Kruskal-Wallis test, whi$\mathrm{ch}$ is a non-parametric technique that was used to confirm acceptance or rejection of the hypotheses because certain data are not normally distributed for the two independent variables analyzed in this situation. This technique was also applied to test the other hypotheses. 


\begin{tabular}{|c|c|c|c|c|c|c|c|}
\hline \multirow{2}{*}{\multicolumn{2}{|c|}{$\begin{array}{l}\text { Expected Relationship: } \\
\text { Slack (BSS) }>\text { (BSNS) } \\
\text { Honesty (BSS) < (BSNS) }\end{array}$}} & \multirow[b]{2}{*}{ Mean } & \multicolumn{2}{|c|}{ ANOVA Parametric Test } & \multicolumn{3}{|c|}{ Non-Parametric Test - Kruskal-Wallis } \\
\hline & & & $\mathbf{F}$ & Sig & Ranking & Q & Sig \\
\hline \multirow{2}{*}{ Budgetary Slack } & Not shared (BSNS) & 684.34 & 11.331 & 0.001 & 99.88 & 5.951 & 0.015 \\
\hline & Shared (BSS) & 413.93 & & & 81.12 & & \\
\hline \multirow{2}{*}{ Honesty } & Not shared (BSNS) & 0.654 & 0.745 & 0.389 & 87.70 & 0.532 & 0.466 \\
\hline & Shared (BSS) & 0.696 & & & 93.30 & & \\
\hline
\end{tabular}

Source: Study data.

Table 3 shows significance at the $5 \%$ level for the condition in which budgetary slack is shared with the assistant, with an F-Statistic of 11.331 and significance of 0.001 . With respect to honesty, the F-Statistic of 0.745 and significance of 0.389 did not reach the $5 \%$ level of significance, indicating high variance of the indices between the situations analyzed. These results were confirmed by the non-parametric test, which suggests a trend in the data.

Despite the smaller variation between the mean accuracy values ( 0.654 and 0.696$)$ than between the mean slack values (684.34 and 413.93), the results suggest that managers report with less accuracy when the benefit of slack is not shared with assistants. Thus, hypothesis $\mathrm{H}_{1}$, which assumes that managers report with less accuracy when the benefit of slack is shared with assistants than when the benefit of slack is not shared, is rejected.

These results conflict with Bandura's (1990, 1999, 2002) argument that shared interest in slack provides a justification for managers to create higher budgetary slack values and prepare less accurate budget reports. The managers' behavior in this study indicates that the creation of higher levels of budgetary slack is aligned with self-interest and not with self-justification based on the collective good, as proposed by the moral disengagement theory (Bandura, 1990, 1999, 2002).

The second set of hypotheses aims to test whether managers report with greater accuracy when their assistants are aware of the managers' reporting behavior and the benefit of the slack is not shared $\left(\mathrm{H}_{2 \mathrm{a}}\right)$ and whether the accuracy of the budget reports is unaffected by the assistants' knowledge of the managers' reporting behavior when the benefit of slack is shared $\left(\mathrm{H}_{2 \mathrm{~b}}\right)$. The $\mathrm{t}$-test performed showed homoscedasticity of the data for both slack and honesty.

Table 4 presents the results of the statistical tests related to whether the accuracy of budget reports is affected by the assistant's ignorance/knowledge of budgetary slack when the benefits of slack are not shared $\left(\mathrm{H}_{2 \mathrm{a}}\right)$.

Table 4 Accuracy when budgetary slack is not shared according to assistant's ignorance/knowledge of budgetary slack

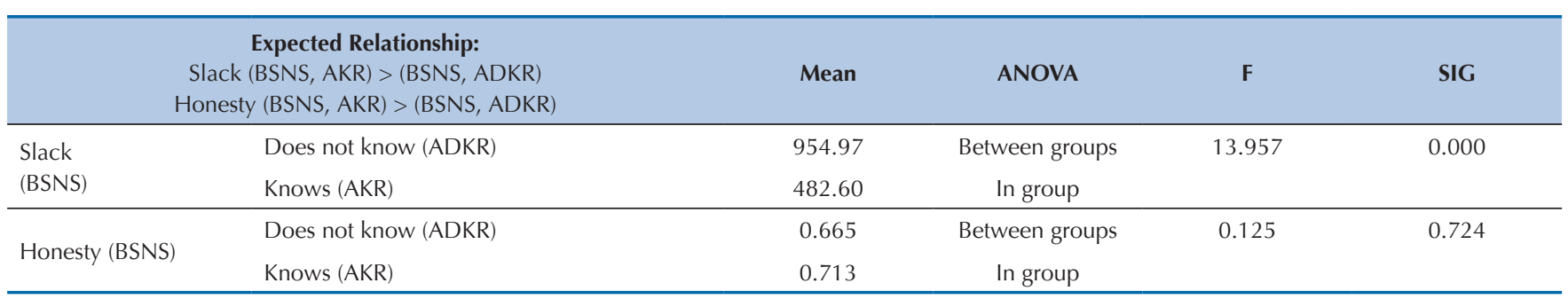

Source: Study data.

Table 4 shows that the ANOVA test presents a statistical explanation for the variation between the conditions analyzed (does not know and knows), with an $F$ -Statistic of 13.957 and significance of 0.000 for the slack variable. Therefore, if the benefit of slack is not shared with assistants and assistants do not know the managers' reporting behavior, managers tend to have lower indices of honesty (0.665) than when assistants have knowledge of the managers' reporting behavior (0.713). These results do not allow the rejection of hypothesis $\mathrm{H}_{2 \mathrm{a}}$ and are consistent with the results of Abul-Ezz and Dickhaut
(1993), which show the influence of social norms on individuals' behavior, and of Church et al. (2012), which highlight managers' concerns about conveying an opportunistic and selfish image to their assistants.

The analysis of whether the accuracy of the manager's report is unaffected by the assistant's awareness of the manager's reporting behavior when the benefit of slack is shared $\left(\mathrm{H}_{2 \mathrm{~b}}\right)$ shows a homogeneous distribution for the slack variable but not for the honesty variable, due to the variability of variances, as shown in Table 5 . Table 5 also shows the results for the non-parametric test. 
Accuracy when slack is shared according to assistant's ignorance/knowledge of budgetary slack

\begin{tabular}{|c|c|c|c|c|c|c|c|}
\hline \multirow{2}{*}{\multicolumn{2}{|c|}{$\begin{array}{c}\text { Expected Relationship: } \\
\text { Slack and Honesty }(B S S, A K R)=(B S S, A D K R)\end{array}$}} & \multirow{3}{*}{$\begin{array}{c}\text { Mean } \\
255.33\end{array}$} & \multicolumn{2}{|c|}{ ANOVA Parametric Test } & \multicolumn{3}{|c|}{ Non-Parametric Test - Kruskal-Wallis } \\
\hline & & & \multirow{2}{*}{$\frac{\text { F }}{6.437}$} & \multirow{2}{*}{$\frac{\text { Sig }}{0.013}$} & \multirow{2}{*}{$\frac{\text { Ranking }}{40.43}$} & \multirow{2}{*}{$\frac{\mathrm{Q}}{3.466}$} & \multirow{2}{*}{$\frac{\text { Sig }}{0.063}$} \\
\hline Slack & Does not know (ADKR) & & & & & & \\
\hline (BSS) & Knows (AKR) & 430.88 & & & 50.57 & & \\
\hline \multirow{2}{*}{$\begin{array}{l}\text { Honesty } \\
\text { (BSS) }\end{array}$} & Does not know (ADKR) & 0.634 & 0.122 & 0.728 & 46.96 & 0.286 & 0.593 \\
\hline & Knows (AKR) & 0.607 & & & 44.04 & & \\
\hline
\end{tabular}

Source: Study data.

The descriptive results and ANOVA test shown in Table 5 lead to the rejection of hypothesis $\mathrm{H}_{2 \mathrm{~b}}$ because the $F$-Statistic of 6.437 and significance of 0.013 indicate significant coefficients for slack but do not show significance for honesty, given the variability of the variance. The difference between the values of budgeted slack when the assistant is not aware of the manager's reporting behavior (255.33) and when the assistant is aware of the manager's reporting behavior (430.88) indicates that the accuracy of budget reports is affected by the assistant's knowledge, even if the benefit of slack is shared.

The results for the second set of hypotheses $\left(\mathrm{H}_{2 \mathrm{a}}\right.$ and $\mathrm{H}_{2 \mathrm{~b}}$ ) are in line with Hsee's theory of elasticity (1995, 1996), which predicts that the manager's reporting behavior is influenced by whether the assistant knows or does not know of the creation of slack, which affects the elasticity of the manager's actions.

The rejection of hypothesis $\mathrm{H}_{2 \mathrm{~b}}$ is noteworthy. According to Bandura $(1990,1999,2002)$, the sharing of slack provides self-justification for the preparation of less accurate budget reports. However, the evidence in this study reveals that the managers were more concerned about group regulation (Abul-Ezz \& Dickhaut, 1993; Rankin et al., 2005; Church et al., 2012) than about self-regulation (Bandura, 1999, 2002).

\subsection{Results of the Second Part of the Experiment}

The second part of the experiment tested the theory of elasticity by analyzing whether the assistants' preferences regarding slack influenced managers' reporting behavior (Hsee, 1995, 1996). To this end, the assistants were asked to indicate the extent to which they agreed that the budget should be inflated.

Of the 45 assistants participating in the experiment, 21 respondents indicated a preference for budgets without slack, fourteen respondents indicated a preference for budgets with slack, and 10 respondents indicated indifference to the inclusion of budgetary slack.

Each assistant was randomly assigned to a manager, and each manager was made aware of his/her assistant's preference regarding slack. Then, the manager prepared a budget report with knowledge of the assistant's opinion. A means test was conducted to determine the normality of the variables and to guide the selection of the statistical technique that best fit the data. Table 6 presents the results of the tests that contribute to the analysis of hypotheses $\mathrm{H}_{3}$ and $\mathrm{H}_{4}$.

Table 6 Accuracy of the budget reports according to assistant's preference

\begin{tabular}{|c|c|c|c|c|c|c|c|}
\hline \multirow{2}{*}{\multicolumn{2}{|c|}{$\begin{array}{c}\text { Expected Relationship } \\
\text { Slack }(\text { KAP-H })<(\text { KAP-S, KAP-I) } \\
\text { Honesty }(\text { KAP-H })>(\text { KAP-S, KAP-I) }\end{array}$}} & \multirow{2}{*}{$\mathbf{N}$} & \multirow{2}{*}{ Mean } & \multirow{2}{*}{ Standard Deviation } & \multicolumn{3}{|c|}{ Kruskal-Wallis } \\
\hline & & & & & Ranking & $\mathbf{Q}$ & Sig \\
\hline \multirow{2}{*}{ Slack } & Preference (KAP-H) & 21 & 628.09 & 744.16 & 23.52 & 0.066 & 0.798 \\
\hline & Preference (KAP-S; KAP-I) & 24 & 592.70 & 687.91 & 22.54 & & \\
\hline \multirow{2}{*}{ Honesty } & Preference (KAP-H) & 21 & 0.64 & 0.42 & 22.48 & 0.066 & 0.798 \\
\hline & Preference (KAP-S; KAP-I) & 24 & 0.66 & 0.39 & 23.46 & & \\
\hline \multirow{2}{*}{\multicolumn{2}{|c|}{$\begin{array}{l}\text { Expected Relationship } \\
\text { Slack and Honesty }(\text { KAP-S })=(\text { KAP-I) }\end{array}$}} & \multirow{2}{*}{$\mathrm{N}$} & \multirow{2}{*}{ Mean } & \multirow{2}{*}{ Standard Deviation } & \multicolumn{3}{|c|}{ ANOVA } \\
\hline & & & & & $\mathrm{F}$ & & $\mathrm{F}$ \\
\hline \multirow{2}{*}{ Slack } & Preference (KAP-S) & 14 & 351.78 & 529.37 & \multicolumn{2}{|l|}{4.802} & 0.39 \\
\hline & Preference (KAP-I) & 10 & 930.00 & 766.73 & & & \\
\hline \multirow{2}{*}{ Honesty } & Preference (KAP-S) & 14 & 0.80 & 0.30 & \multicolumn{2}{|l|}{4.809} & 0.039 \\
\hline & Preference (KAP-I) & 10 & 0.47 & 0.43 & & & \\
\hline
\end{tabular}


Table 6 shows that the managers who know that their assistants preferred honest budgets (mean 0.64 and standard deviation 0.42) present less accurate budget reports (mean 628.09 and standard deviation 744.16). This finding contradicts $\mathrm{H}_{3}$ 's prediction that the budget reports prepared by managers who know that their assistants prefer honest budgets will be more accurate than the budget reports prepared by managers who know that their assistants either prefer slack or are indifferent to slack. However, according to the Kruskal-Wallis test (a nonparametric test, given the non-normality of the data), there is no significant difference between the three situations, which does not allow hypothesis $\mathrm{H}_{3}$ to be rejected.

Therefore, the results indicate that the creation of slack by participant-managers in this experiment is not linked with self-justification based on their assistants' preferences for slack, which contradicts the theory of elasticity (Hsee, 1995). The results differ from what is expected, namely, that slack would be smaller when the manager is aware of the assistant's preference for honest budgets (KAP-H) than when the manager knows that the assistant prefers budgets with slack (KAP-S) or that the assistant is indifferent to the inclusion of budgetary slack (KAP-I).

Hypothesis $\mathrm{H}_{4}$ predicts that the accuracy of budget reports does not differ between managers who know that their assistants prefer the inclusion of slack in budgets and managers who know that their assistants are indifferent to the practice of slack. However, the application of the ANOVA statistical test (a parametric test, given the normality of the data) shows higher mean slack values (mean 930.00 and standard deviation 766.73) and a lower honesty index (mean 0.47 and standard deviation 0.43 ) when the manager knows that the assistant is indifferent to slack. In addition, the difference between the observed situations is significant at the $5 \%$ level, which leads to the rejection of $\mathrm{H}_{4}$.
These results suggest that as in the previous situation, the managers' reporting behavior does not align with their assistants' preference regarding slack, which is inconsistent with the theory of elasticity (Hsee, 1995). Thus, the result differs from the prediction that slack would not differ between managers who are aware of their assistants' preference for budgets with slack (KAP-S) and managers who know that their assistants are indifferent to slack (KAP-I).

In sum, the results obtained in the second part of the experiment are not consistent with either the moral disengagement theory (Bandura, 1990, 1999, 2002) or the theory of elasticity (Hsee, 1995, 1996). This inconsistency suggests that the budget process in the second part of the experiment may have been influenced by other variables, such as the above-mentioned limitations of the experimental design or even the specific characteristics of the study participants given the organizational culture of which they are part. This issue provides an interesting field for future research.

To finish the experiment, a post-experiment questionnaire was administered to the managers to determine the extent to which they cared about their assistants' preferences regarding the creation of slack when preparing the budgets. Of the 45 respondents, the vast majority (38 managers) indicated that they considered their assistant's opinion to be very important.

However, when comparing the questionnaire responses with the statistics presented in Table 6, it appears that the highest slack means occur when the manager knows that the assistant prefers honest budgets (without slack), which indicates that the managers' reporting behavior is based on their own interests and that the assistants' preference for slack is not necessarily used as a justification factor for slack creation (Hsee, 1995). These results may reflect a unique characteristic of the sample, which indicates the need for further studies.

\section{FINAL CONSIDERATIONS}

This study investigated how shared interests in budgetary slack affect the accuracy of budget reports. Experimental research was conducted on a sample of 90 employees with management and leadership roles in a production cooperative in the South of Brazil. Data collection was accomplished using the procedures of the study by Church et al. (2012), with certain adjustments. In the statistical analysis of the data, the means and standard deviations were calculated to determine the slack and the level of accuracy of the budgets, and ANOVA and Kruskal-Wallis tests were used to test the hypotheses in each of the two stages of the experiment.

The results of the first part of the experiment show great variation among the means of each experimental condition. For example, when slack is not shared, the ac- curacy index for budgets is lower (more slack was created) when the assistant does not have knowledge of the manager's reporting behavior than when the assistant has knowledge of manager's reporting behavior. When slack is shared, the results showed a higher mean slack when the assistant is aware of the manager's reporting behavior.

The results indicated that managers report with less accuracy when the benefit of slack is not shared with assistants. Thus, hypothesis $\mathrm{H}_{1}$, which states that managers present less accurate budget reports when the benefit of slack is shared with assistants than when the benefit is not shared, is rejected. These results are inconsistent with the argument of Bandura $(1990,1999,2002)$ that shared interest in slack provides a justification for managers to present less accurate budget reports. 
With respect to the second set of hypotheses, it was found that when the benefit of slack is not shared with assistants, managers tend to report with greater accuracy when the assistants are aware of the creation of slack than when the assistants are not aware of the creation of slack. Therefore, hypothesis $\mathrm{H}_{2 \mathrm{a}}$ is not rejected This result is consistent with the findings of Abul-Ezz and Dickhaut (1993) and Church et al. (2012) regarding managers' concerns about conveying an opportunistic and selfish image to their assistants. However, when the benefit of slack is shared with the assistants, the accuracy of the managers' budget reports is affected by the assistants' knowledge of the managers' reporting behavior; therefore, hypothesis $\mathrm{H}_{2 \mathrm{~b}}$ is rejected. This result is inconsistent with Bandura's $(1990,1999,2002)$ proposal that sharing provides self-justification for the submission of less accurate budget reports.

The second part of the experiment aimed to investigate whether the assistants' preferences regarding the creation of slack influence managers' behavior. The results showed that managers had a higher accuracy index when the manager knows that the assistant prefers a budget with slack and thus hypothesis $\mathrm{H}_{3}$ is rejected. In addition, the accuracy index differs between managers who know that their assistants preferred slack and managers who know that their assistants are indifferent to slack, which implies the rejection of hypothesis $\mathrm{H}_{4}$. Therefore, the evidence shows that the managers' reporting behavior is not affected by managers' unawareness/awareness of their assistants' preferences/indifference regarding the creation of slack but rather is based on the manager's own preferences. These results contradict the theory of elasticity (Hsee, 1995).

A comparative analysis of the means from this study with the means from the study of Church et al. (2012) shows that in the present study, there is greater variation between the means of the slack values for the different situations analyzed, which is also reflected in the accuracy indices of the budget reports. These results indicate that the managers in this study cared more about their assistants' preference regarding slack than the managers in Church et al. (2012); however, the results also reveal that managers' reporting behavior was motivated by self-interest. As for the hypotheses tested in the two studies, only the failure to reject hypothesis $\mathrm{H}_{2 \mathrm{a}}$ was congruent between them. Tests of the other hypotheses $\left(\mathrm{H}_{1}, \mathrm{H}_{2 b}, \mathrm{H}_{3}\right.$ and $\mathrm{H}_{4}$ ) in this study produced results that differed from the results of the baseline study.

It is therefore concluded that the results of this study differ in several respects from the results of Church et al. (2012). One possible explanation for the differences may be the perceptions of the sample participants in this study, who address the budget process phenomenon in their daily lives. Despite the parsimony of the analyses, the results may also have been affected by the need to make certain inferences regarding the experimental design and by the modifications made to the experimental design. In addition, adjustments related to sample selection (random selection between managers and leaders for the roles of managers and assistants) and experimental conditions (a cooperative that uses the budget as a management tool and as a basis for the variable compensation of employees).

Thus, this study helps to expand the discussion of Church et al. (2012) regarding the influence of shared interests on the accuracy of budgets, especially because this study obtained different results by conducting the experiment based on a hypothetical situation (Gall, Gall, \& Borg, 2007; Smith, 2011) that simplified the budgeting process in an organization under certain moderating conditions and used a sample of professionals who were accustomed to or at least knowledgeable about the application of budgeting processes in organizational practice. Thus, it is recommended that additional empirical studies be conducted in organizations that use budgeting in management to test whether the differences observed in this study are maintained and to develop possible explanations for these differences.

\section{References}

Abul-Ezz, M. E., \& Dickhaut, J. W. (1993). Incentive structure and group performance expectations in a budgeting setting: a descriptive study Accounting, Auditing \& Accountability Journal, 6 (2), 17-31.

Aguiar, A. B., \& Souza, S. M. (2010). Processo orçamentário e criação de reservas em uma instituição hospitalar. Revista Contemporânea de Contabilidade, 1 (13), 107-126.

Bandura, A. (1990). Selective activation and disengagement of moral control. Journal of Social Issues, 46 (1), 27-46.

Bandura, A. (1999). Moral disengagement in the perpetration of inhumanities. Personality and Social Psychology Review, 3 (3), 193-209.

Bandura, A. (2002). Social cognitive theory in cultural context. Applied Psychology, 51 (2), 269-250.

Beuren, I. M., \& Paton, C.(2013). Folga organizacional em unidades de negócios de empresa descentralizada na percepção dos controllers. Pretextus, 14 (1), 13-35.

Buzzi, D. M., Santos, V., Beuren, I. M., \& Faveri, D. B. (2014). Relação da folga orçamentária com participação e ênfase no orçamento e assimetria da informação. Revista Universo Contábil, 10 (1), 06-27.

Bruns, W. J., \& Waterhouse, J. H. (1975). Budgetary control and organization structure. Journal of Accounting Research, 13 (2), 1.77-203.

Chow, C. W., Cooper, J. C., \& Waller, W. S. (1988). Participative budgeting: effects of a truth-inducing pay scheme and information asymmetry on slack and performance. The Accounting Review, 63 (1), 111-122.

Church, B. K., Hannan, R. L., \& Kuang, X. (2012). Shared interest and honesty in budget reporting. Accounting, Organizations and Society, 37 (3), 155-167.

Covaleski, M. A., Evans, J. H., III, Luft, J. L., \& Shields, M. D. (2003). Budgeting research: three theoretical perspectives and criteria for selective integration. Journal of Management Accounting Research, 15 (1), 3-49.

Davila, T., \& Wouters, M. (2005). Managing budget emphasis through the explicit design of conditional budgetary slack. Accounting, Organizations and Society, 30 (7/8), 587-608.

Dunk, A. S. (1993). The effect of budget emphasis and information asymmetry on the relation between budgetary participation and slack. The Accounting Review, 68 (2), 400-410.

Dunk, A. S., \& Nouri, H. (1998). Antecedents of budgetary slack: a literature review and synthesis. Jourrial of Accounting Literature, 17 (1), 72-96.

Dunk, A. S., \& Perera, H. (1997). The incident of budgetary slack: a field study exploration. Accounting, Auditing and Accountability Journal, 10 (5), 649-664. 
Evans, J. H., III, Hannan, R. L., Krishnan, R., \& Moser, D. V. (2001). Honesty in managerial reporting. The Accounting Review, 76 (4), 537-559.

Faria, J. A. (2012). A folga orçamentária sob a perspectiva da assimetria da informação para usuários internos. Revista de Administração e Contabilidade da FAT, 4 (3), 31-51.

Frezatti, F., Beck, F., \& Silva, J. O. (2013). Percepções sobre a criação de reservas orçamentárias em processo orçamentário participativo. Revista de Educação e Pesquisa em Contabilidade, 7 (4), 335-354.

Frezatti, F., Nascimento, A. R., Junqueira, E., \& Relvas, T. R. S. (2011). Processo orçamentário: uma aplicação da análise substantiva com utilização da Grounded theory. O\&S Organizações \& Sociedade, 18 (58): $445-466$

Gall, M. D., Gall, J. P., \& Borg, W.R. (2007). Educational research (8th ed., p. 672). Boston: Pearson.

Hartmann, F. G. H., \& Maas, V. S. (2010). Why business unit controllers create budget slack: involvement in management, social pressure, and machiavellianism. Behavioral Research in Accounting, 22 (2), 27-49.

Hollensbe, E. C., \& Guthrie, J. P. (2000). Group pay-for-performance plans: the role of spontaneous goal setting. The Academy of Management Review, 25 (4), 864-872.

Hsee, C.K. (1995). Elastic justification: how tempting but task-irrelevant factors influence decisions. Organizational Behavior and Human Decision Processes, 62 (3), 330-337.

Hsee, C. K. (1996). Elastic justification: how unjustifiable factors influence judgments. Organizational Behavior and Human Decision Processes, 66 (1), 122-129.

Junqueira, E., Oyadomari, J. C., \& Moraes, R. O. (2010). Reservas orçamentárias: um ensaio sobre os fatores que levam à sua constituição. ConTexto, 10 (17), 31-42.

Kilfoyle, E., \& Richardson, A. J. (2011). Agency and structure in budgeting: thesis, antithesis and synthesis. Critical Perspectives on Accounting, 22 (2), 183-199.

Lal, M., Dunk, A. S., \& Smith, G. D. (1996). The propensity of managers to create budgetary slack: a cross-national re-examination using Random Sampling. The International Journal of Accounting, 31 (4), 483-496.

Lavarda, C. E. F., \& Fank, O. (2014). Relação da assimetria da informação, 'da participação orçamentária e do risco na criação da folga orçamentária. Contextus, 12 (1), 81-110.

Lukka, K. (1988). Budgetary biasing in organizations: theoretical framework and empirical evidence: Accounting, Organizations and Society, 13.(3), 281-301.
Maiga, A. S., \& Jacobs, F. A. (2008). The moderating effect of manager's ethical judgment on the relationship between budget participation and budget slack. Advances in Accounting, 23 (1), 113-145.

Merchant, K. A. (1985). Budgeting and the propensity to create budgetary slack. Accounting, Organizations and Society, 10 (2), 201-210.

Moene, K. (1986). Types of bureaucratic interaction. Journal of Public Economics, 29 (3), 333-345.

Moore, C. (2008). Moral disengagement in processes of organizational corruption: The effect of moral disengagement. Doctoral dissertation, University of Toronto, Toronto, Canada.

Nouri, H., \& Parker, R. J. (1998). The relationship between budget participation and job performance: the roles of budget adequacy and organizational commitment. Accounting, Organizations and Society, 23 (5/6), 467-483.

Osofsky, M. J., Bandura, A., \& Zimbardo, P. G. (2005). The role of moral disengagement in the execution pröcess. Law and Human Behavior, 29 (4), 371-393.

Pereira, A. G., Bruni, A. L., \& Cordeiro Filho, J. B. (2012). Hiatos de racionalidade e decisões gerenciais: perspectivas sobre a "caixa preta" do profissional de controladoria. Revista de Contabilidade do Mestrado em Ciências Contábeis da UERJ (Online), 17 (1), 65-76.

Quintas, T. T., \& Beuren, I. M. (2011). Abordagens sobre folga organizacional nas pesquisas publicadas em periódicos internacionais. Revista de Administração da UFSM, 4 (1), 53-72.

Rankin, F. W., Schwartz, S. T., \& Young, R. (2005). The effect of honesty and superior authority on budget proposals. Available at http://www.cob. ohio-state.edu/ young_53/Honesty_Authority.pdf.

Simons, R. (1995). Levers of control. Boston: Harvard Business School Press.

Simith, M. (2011). Research methods in accounting (2nd ed., p. 223). London: Sage.

Van der Stede, W. A. (2000). The relationship between two consequences of budgetary controls: budgetary slack creation and managerial short-term orientation. Accounting Organizations and Society, 25 (6), 609-622.

Waller, W. S. (1988). Slack in participative budgeting: the joint effect of a truth-inducing pay scheme and risk preference. Accounting Organizations and Society, 13 (1), 87-98.

Yuen. D. C. Y. (2004). Goal characteristics, communication and reward systems, and managerial propensity to create budgetary slack. Managerial Auditing Journal, 19 (4), 517-532. 